\title{
Correspondence
}

Letters to the Editor should not exceed 500 words.

\section{Psychotropic Drugs}

SIR,-Dr. J. T. Hutchinson's suggestion (2 December, p. 555) of using the suicide rate as a guide to the value or otherwise of antidepressant medication seems reasonable enough. However, the figures I have available do not appear to be encouraging. Assuming that the great majority of suicides are caused by depressive states, one would expect a significant drop in the overall rate for England and Wales. But the figure per 100,000 has been fairly constant ${ }^{1}$ during the years 1954 to 1964 at 11 to 12 -lowest 11.3 in 1960, highest 12.15 in 1963 . Of course it may be that some deleterious factor other than depression has been increasing over the gears and counteracting the preventive influences of antidepressant drugs. Or has the severity of depressive states become more intense ? Or has the incidence of depression increased ? I doubt whether there are reliable statistics to answer these questions. Practical psychiatrists are too busy to grade the severity of depressions accurately enough for research purposes; and not so long ago conditions which are now classified as "masked depression" were given all sorts of other labels. - I am, etc.,

$$
\begin{aligned}
& \text { Weybridge, } \\
& \text { Surrey, }
\end{aligned}
$$

I. Atkin.

Surrey.

\section{REPERENCB}

$\{$ Registrar General's Statistical Revierw of England Registrar Weneral's Statistical Review of tor the year 1964, Part I, Tables,
and Wedical, 1966. H.M.S.O.

SIR,-I could not agree more with your correspondent Dr. J. T. Hutchinson when he states in the B.M.F.: "It is time that clinicians ceased to be afraid of the dangers of these drugs" (2 December, p. 555). I am sure I speak for hundreds of general practitioners when I affirm that the use of antidepressant drugs (and this certainly includes monoamine oxidase inhibitors) has revolutionized the treatment of depressive illness in family practice.

My partner and I have about 150 patients suffering from various forms of depressive illness in our practice, and half of these attend intermittently for further supplies of antidepressive drugs. They are not asked to do so, but have found from their own experience that the various manifestations of depressive illness are helped by these drugs in a way no other treatment can equal. We have not had a single suicide in the past six years.

There is no doubt whatever that the use of these drugs has greatly added to the satisfaction that the family doctor can get from the management of a wide variety of illnesses that in the past were a source of continuing frustration and anxiety to him. In this context, as a family doctor long interested in psychiatric illness, I feei that the concept by Sargant and others of the wide anxietydepression spectrum of illness ${ }^{1}$ is one of great interest to general practitioners and one with which they can wholeheartedly agree.

Amitriptyline and nortriptyline are increasingly used, but Parstelin and phenelzine are still very useful in general practice, reactions to them being very rare; and there remains a definite place for the use of a short-term liquid amphetamine preparation for "post-influenzal debility" and the like. -I am, etc.

Leeds 17.

\section{Alastair U. MAcKinnon.} REPERENCB

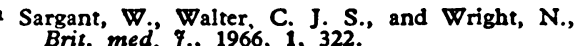

SIR,-Dr. J. T. Hutchinson in his concern for the patient needs no support (2 December, p. 555). That he has seen only one death due to drugs in eight years may well depend on what drugs he has tried and in what dosage and combination; two of my patients on a pre-marketing drug trial fared badly: I abandoned this trial and the drug was later withdrawn.

Linking the suicide rate with the efficacy

of drugs is reasonable enough, but one must take account of the management of the patient, which includes the availability of lethal drugs and of clinical assessment, which needs to be reviewed repeatedly for each patient. It is not an overstatement that every depressed patient presents a suicidal risk which one might avoid by admission and fulltime observation, but in general a calculated risk has to be taken during the whole course of the illness, particularly when initiative returns.

My own general approach is to separate patients suffering from depressive symptoms -unhappiness, guilt, unworthiness, and hopelessness-and to administer as a first choice convulsive therapy, which is still the most effective and the quickest mode of treatment. I use drugs first for those patients whose "depressive" state needs to be diagnosed and is not self-evident-for instance, preoccupation with spectacles and dentures, fatigability, impaired interests, various chronic somatic symptoms, and so on. These patients hardly ever constitute a suicidal risk, so that the manipulation of drugs until a suitable dosage or combination is found is valid and safe ; if this is not achieved convulsant therapy is often effective. Of course by this time the natural history of the illness may also be a factor in improvement.-I am, etc.,

London W.1.

L. Rose.

\section{Clomiphene for Ovulation}

SIR,-The letter from Dr. P. M. F. Bishop (9 December, p. 617) highlights the dilemma about the proper way to use clomiphene. On the one hand, there is much to be said for Dr. Bishop's view that as the drug appears harmless and as its sole purpose is to stimulate ovulation it should be freely used without elaborate scientific controls. Not many would agree with his implication that the main purpose of the steroid chemists is "to get on with their research work," but the central point is well taken. On the other hand, the induction of ovulation and subsequent fertilization is not a casual process or a frequent demand on the Health Service and it is not unduly fussy to treat the matter with some circumspection.

There are three good reasons for supporting the view taken in your leading article (25 November, p. 434) that accurate hormone assays should be used in connexion with clomiphene administration. The first is in selecting suitable women for the treatment ; particularly in identifying those amenorrhoeic subjects with sufficient residual ovarian activity to respond to the treatment, or the women with regular but persistently anovular cycles. Dr. Bishop argues well for vaginal cytology as a compromise between no controls and proper hormone assays, particularly as he has himself done much to popularize these services, but few would deny that they are inferior to hormone assays, and they are inadequate for categorizing the women sub- jected to the treatment or determining the nature and timing of their response.

The second reason for the use of hormone assays is that they make it possible to fix the day of ovulation with much more accuracy than by vaginal cytology. Indeed the most advanced laboratory services claim to be able to predict the day of ovulation from the rising oestrogen curve and usually advise about the timing of intercourse. At worst, one has valuable data about the pattern of response, which is likely to repeat itself in subsequent courses. The third reason is that hormone assays give quantitative information about the nature of the response. One can tell whether there was any ovarian response, whether the oestrogen excretion was equal to or much above that of the normal cycle, and whether or not it was followed by ovulation and how adequate the luteal phase was. The incidence of multiple pregnancy and of ovarian cyst formation appears to be related to the nature of the ovarian response, which in its turn is a dose-related phenomenon. Accurate information about the ovarian response enables the physician to regulate dosage in subsequent treatments.

I believe that these reasons are sufficiently compelling to justify some voluntary restriction of the freedom of the individual doctor to give his patient whatever treatment he chooses. It is a besetting fact of medicine in our time that it is passing from the individual to the team and from the man to the 
institution. As laboratories cannot be brought to patients, patients must sometimes be brought to laboratories. On balance this seems to be a situation where this applies.I am, etc.,

$$
\begin{aligned}
& \text { University of Aberdeen, } \\
& \text { Aberdeen. }
\end{aligned}
$$$$
\text { Aberdeen. }
$$

\section{Using Computers}

SIR,-The paper by Mr. S. P. Watts and Dr. E. D. Acheson (25 November, p. 476) calls for two comments. Their study is not essentially a computer method in the accepted sense of the term. It has been done manually. It could certainly be done with business machines. Of course, it is easier with a computer. Hospital activity analysis can provide "treatments" or "persons." It is a matter of input organization (an identity-fix in particular) and programming. There is no "error" between one and the other. They are different things. For year-to-year comparisons "treatments" may be a sufficient indicator. For true morbidity measurements "persons" are inadequate, since they form only the hospital tip of the iceberg.

But, as in all statistics, it depends on what you want to use the rates for. If it is for hospital management-for example, the efficient use of resources-then the "spell" is the right unit. If for disease managementfor example, for diagnosis symptom matrices -then the individual "person" record updated with the whole medical history (inside or outside the hospital)-that is, a fullblooded community health record systemis needed.

Hospital activity analysis is intended to lead into this, ${ }^{\prime}$ and some experiments are already being made to extend hospital activity analysis in this direction. In the long run the unified record will pay bigger dividends than record linkage.-I am, etc.,

$$
\begin{aligned}
& \text { BERNARD BENJAMIN, } \\
& \text { Director, } \\
& \text { Research and Intelligence Unit, } \\
& \text { Greater London Council. }
\end{aligned}
$$

London S.E.1.

\section{REFBRENCB} - Benjamin, B., Proc. roy. Soc. Med., 1967, 60,
809 .

$\checkmark$

\section{Animal Reservoirs of Salmonellae}

SIR,-I read with interest Dr. L. T. Newman's letter (4 November, p. 296) on the dangers of salmonella infections from pet tortoises and Dr. W. H. Parry's (25 November, p. 486) on the similar dangers from a pet terrapin. I am glad they have stressed the very real risks of animal reservoirs of intestinal infection which so often go unrecognized. Salmonella infections are far from rare ${ }^{1}$ and thousands of new cases occur each year in Britain. In 1965 there were 832 cases of paratyphoid fever alone in England and Wales. The paratyphoid fevers may not always cause gastrointestinal symptoms and the carrier state is common and difficult to eradicate. ${ }^{2}$ In addition to the typhoid and paratyphoid fevers salmonella infections may be far from minor illnesses," and a single outbreak in Sweden of Salmonella typhimurium was reported which caused 7,717 cases with 90 deaths.

Certain preserved foods are universally recognized as potential sources of salmonella infections. It is not so well known that nearly every animal in the world, both wild and tame, may carry salmonellae in its gastrointestinal tract, including dogs, foxes, horses, cattle, swine, sheep, goats, hedgehogs, pigeons, and even the ticks, lice, and fleas that feed on infected swine and other animals. Even the lion is not exempt, ${ }^{3}$ though it could hardly be classified as a pet except perhaps in Ethiopia.

Pet tortoises are a real hazard, but reported infections in iguanas, snakes, and lizards ${ }^{6}$ are more academic than real. As the festive season approaches, however, it is a salutary thought to remember that domestic poultry constitutes the largest single reservoir in nature and that turkeys are especially affected. Some $41 \%$ of turkeys in California were found infected with salmonellae.' The canary may be affected ${ }^{3}$ and the dog is a frequent host. In 100 dogs examined in the U.S.A. 18 were found to have salmonella infections, most of which were pathogenic for man. In Norway an infected dog was found to be responsible for six cases of paratyphoid in human beings. ${ }^{10}$ In Florida greyhounds were routinely tested, and between $32 \%$ and $55 \%$ of all dogs were found to be carriers of salmonellae. ${ }^{11}$ Dogs, after swine, were found to be the most important asymptomatic carriers and $40 \%$ of cases were due to $S$ typhimurium. Dogs and cats have been found to be responsible for $S$. choleraesuis transmission to children, ${ }^{12}$ and $13.2 \%$ of healthy dogs in the U.S.A. were found infected with salmonellae and over $1 \%$ of cats in England.'

Obviously many salmonellae in animals are non-pathogenic for man. A number may be, however, and the possibility of an enteriti being spread by a pet should always be borne in mind, especially in young children with an undiagnosed gastroenteric infection.-I am, etc.

\section{Makerere University College, \\ Kampala, Uganda.}

\section{R. L. HUCRSTEP.}

\section{REFERENCES}

1 Godber, G. E., Annual Report, Ministry of 2 Huckstep, R. L., Curr. Med. Drugs, 1965, 5, No. 6. P. 19 . tions, 1962 . Edinburgh.

- Lundbeck. H., Plazikowski, U., and Silverstolpe,

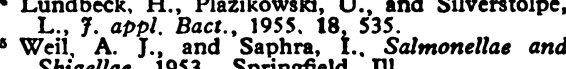
- Shigellae, igs3. Springfield, Mi.

Hinshaw, W. R., and McNeil, B., Y. Bact. (Baltimore), 1947, 53, 715.

- Fey, H. in The World Problem of Salmonellosis. edited by $\mathrm{E}_{\mathrm{B}} \mathrm{L}$. van Oye. 1964 . The Hague. Williams, J. E. in Diseases of Poultry. 1959. 4th Schwarte. Iowa.

Wolf, A. H., Henderson, $N . D_{\text {., }}$ and McCallum, G. L., Amer. A. Publ. Hlth. ig48. 38,403 1937, 10 J. A., Pork. norske. med. Selsk., Stucker, C. L., Galton. M. M., Cowdery, J., and Hardy. A. W., Y. infect. Dis., 1952, 91, 6.
Bruner, D W., and Moran, A. B., Cornell Vet. 1949, 39, 53 .

\section{Improving the Psychiatric Services}

SIR,-There is a great deal of evidence indicating that readmission rates for discharged ex-psychiatric hospital patients are less among those provided with reasonably effective psychiatric aftercare. ${ }^{-4}$

Psychiatric patients can cause great disturbance and trial to others when left at home. Visiting can provide early warning that modification of treatment or persuasion to take tablets has become urgent. Thus in quite a number of these patients a relapse can be averted. I find that a large number stop taking their tablets, and that a recurrence of symptoms within a few weeks follows. When there is no follow-up the patient will of ten not visit a doctor. Relatives are diffident about complaining. Maintenance of morale in many depressive patients does also appear to depend to some extent upon follow-up, and there being somebody, perhaps outside the immediate circle of the patient, giving disinterested help and caring. Dudgeon $^{5}$ noted that as many as $23 \%$ of 471 patients seen a year after leaving mental hospitals had had no contact with a doctor or any other type of trained mental health worker since discharge.

The consequences of a significant number of schizophrenic patients stopping tablets have been outlined. ${ }^{1-4}$ I have seen not one but a number of patients descend to further suicidal attempts following sudden cessation of antidepressant drugs. If in addition to cessation of drugs they are discharged from psychiatric outpatient clinics then it would seem vital that they be visited by someone from the mental welfare services.

In 1952 Dr. Arthur Pool initiated a six-week-in, six-week-out geriatric service in Oldham, with an associated day hospital. This alleviated the situation and did relieve many people with elderly relations as well as the patients. Spread of this system would appear to be well worth while and within the scope of numbers of existing institutions and staffs. As part of this scheme all relatives undertook to have their patients home at the end of the period so that everyone could benefit. They were made to realize that the scheme could only work widely if this was kept to. There was free use of admissions of the elderly, so that the relations who were doing their bit by keeping them at home could get off for needed holidays. Keystones in this system were the co-operation of geriatricians and of the ambulance department, which we had.-I am, etc.,

Colchester

HARRY JACOBS.

Essex.

REFERENCES

Sheldon, A., Brit. F. Psychiat., 1964, 110, 662

${ }_{3}^{2}$ Engelhardt, D. M. Rosen, B., Freedman N., ind Margolis, R., Arch. Gen. Psychiat., 1967, 16,

Pasamanick, B., Scarpitti, F. R., Lefton, M.
Dinitz, S., Wernert, J. J., and McPheeters, H., Dinitz, S., med. Ass., $1964,187,177$

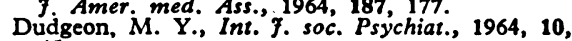
45.

\section{Intussusception Due to Hamartoma}

SIR,-A rare lesion of the base of the appendix may have initiated acute appendicitis and subsequent intussusception of the caecum, and is reported below:

A diagnosis of acute appendicitis was made on a 10-year-old boy, and at operation an acutely inflamed appendix was removed and the stump buried with a purse-string suture. Apart from oedema and local fibrinous exudate over the ileocaecal region no other abnormality was noted. The histology of the excised appendix showed acute appendicitis. After operation he made rapid progress, but on the sixth day complained of colicky abdominal pain. There was some tenderness elicited over the site of the scar, but the symptoms rapidly subsided and he was discharged home on the ninth day,

Two weeks later the patient complained of several brief attacks of colicky central abdominal pain, and during one of these his general prac- 